\title{
INTERPRETAÇÃO INTERLÍNGÜE: AS ESPECIFICIDADES DA INTERPRETAÇÃO DE LÍNGUA DE SINAIS
}

\author{
Maria Cristina Pires Pereira \\ Rede Metodista de Educação do Sul \\ Universidade do Vale do Rio dos Sinos \\ pirespereiramc@gmail.com
}

Resumo: Com o crescente apoio da legislação, a profissão de intérprete de língua de sinais (ILS), no Brasil, vem ganhando, cada vez mais espaço de divulgação. Até recentemente, o público em geral, conhecia somente os intérpretes de conferência de línguas vocais, mas, atualmente, é necessário traçar alguns estudos comparativos entre as duas modalidades de interpretação interlíngüe. Este artigo dispõe-se iniciar um percurso em direção a estes estudos na área da tradução.

Palavras-chave: intérprete de língua de sinais, intérprete de língua vocal, Interpretação interlíngüe.

\begin{abstract}
With the growing support from legislation, sign language interpreter profession, in Brazil, increases more and more its divulgation. Until recent times, people, in general, knew only conference spoken language interpreters but, nowadays, we need to proceed to comparative studies between these two modalities of interlingual interpretation. This article is proposed to begin an investigation towards this area of translation studies.

Keywords: sign language interpreter, spoken language interpreter, interlingual interpretation.
\end{abstract}

Dentre as muitas línguas do Brasil, a língua de sinais brasileira (LSB ou Libras) foi regulamentada pelo Decreto Federal no 5.696, de 22 de dezembro de 2005. Esse apoio da legislação fez com que testemunhássemos, de uma forma impressionante, a visibilidade 
dos intérpretes de língua de sinais (ILS) crescer cada vez mais. Já não é incomum assistir a interpretação em: janelas da televisão, em programas políticos, campanhas governamentais e conferências com a atuação, ao vivo, de ILS. No entanto, a área carece de uma base teórica mais consistente para amparar a formação e os estudos dos ILS. Mesmo quando alça posições nos programas de pós-graduação, o estudo da interpretação de língua de sinais é focado, quase que, exclusivamente, em seu viés educacional relacionado à inclusão escolar das pessoas surdas. Em sua abordagem como um processo entre duas línguas legítimas, como uma interação entre sujeitos e culturas, nos Estudos da Tradução, são bem mais raras as incursões. Infelizmente, a atuação dos ILS é encarada, por boa parte da sociedade, como uma atividade caritativa e assistencial, não como uma profissão que necessita de suporte teórico e que compartilha, com os tradutores e intérpretes de línguas vocais, de muitos aspectos em comum.

Não pretendo fazer aqui, uma revisão do embasamento teórico referente à língua de sinais. Muitas vezes, parece-me que tenho que, a todo momento, justificar a existência dos ILS remetendo a estudos que comprovam o estatuto lingüístico da Libras. Para esta revisão, já existem, no Brasil, obras de grandes pesquisadores

Partirei, então, diretamente dos Estudos da Tradução para fazer minhas disgressões sobre a interpretação de língua de sinais. Pode-se dizer que a tradução é o termo geral que se refere a transformar um texto a partir uma língua fonte, por meio de vocalização, escrita ou sinalização, em outra língua meta. A diferenciação é feita, em um nível posterior de especialização, quando se considera a modalidade da língua para qual está sendo transformado o texto. Se a língua meta estiver na modalidade escrita trata-se de uma tradução; se estiver na modalidade vocal (também chamada de oral) ou sinalizada (presenciais ou de interação imediata), o termo utilizado é interpretação. 


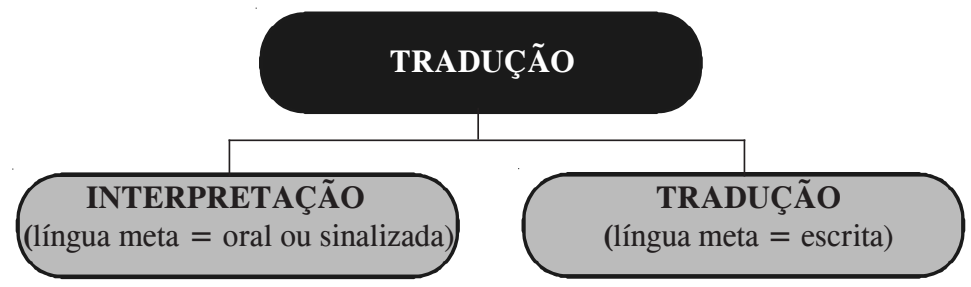

Figura 1 - Diferenciação entre Tradução e Interpretação

O processo de tradução recebe muitas designações: reformulação, retextualização, conversão, transformação, e o tradutor ora é encarado como um mero reprodutor de textos, uma espécie de adaptador de voltagem entre línguas, ora alça a posição de co-autor. Ser intérprete é ser, intrinsecamente, um profissional atormentado por ter que estar presente e fingir-se invisível, algo ainda mais impensável para um intérprete de uma língua que é percebida prioritariamente pelo canal visual, como uma língua de sinais; e por não poder ser o 'eu' nem o 'tu' plenamente, por estar sempre em uma posição instável e escorregadia de um simbiótico locutor-interlocutor. Estes conflitos são maximizados por estereótipos dos quais é difícil nos livrarmos, tais como o velho e surrado traduttori,tradittori, que coloca a profissão sob permanente desconfiança, pois se algo vai mal no ato de linguagem, o primeiro a ser apontado como culpado é o intérprete. Em obras que tratam das pessoas surdas e em que é necessária a interpretação de língua de sinais, esta desconfiança também é demonstrada como, por exemplo, no trecho a seguir:

Sendo baseado apenas no registro oral da tradução via intérprete de LIBRAS, pairaram algumas dúvidas sobre a possibilidade de que, em alguns momentos, o relato dos surdos não tivesse sido fielmente interpretado, a despeito do alto nível de capacitação dos intérpretes (SÁ, 1999, p. 259).

Considerando que, as línguas de sinais ainda possuem a classificação de línguas ágrafas ${ }^{1}$ e não vou me concentrar na língua escri- 
ta, esse artigo traz reflexões sobre o bilingüismo profissional de pessoas que atuam, basicamente, com a interpretação (mediação) interlíngüe entre a Libras e a língua portuguesa brasileira e suas diferenças e similitudes com os intérpretes de línguas vocais.

\section{Intérpretes de Língua de Sinais: de anjos a profissionais}

Diferentemente da Língua Portuguesa ou de qualquer outra língua vocal, a relação entre os elementos lingüísticos, na Libras, se dá, principalmente, pela sua disposição espacial ${ }^{2}$ e este fator é o determinante em várias técnicas de interpretação e de posicionamento dos ILS. Historicamente não é possível rastrear o exato momento em que os intérpretes começaram a atuar, mas é plausível imaginar que desde que povos de diferentes línguas mantiveram contato houve, também, a necessidade de intérpretes. No caso das pessoas surdas, existem hipóteses de que a interpretação surgiu no meio familiar foi, aos poucos, se estendendo aos professores de crianças surdas e ao âmbito religioso. Com o passar do tempo, o fortalecimento dos movimentos sociais e políticos das comunidades surdas e o reconhecimento legal das línguas de sinais surgiu, finalmente, o ILS profissional.

Quando existe a referência a intérpretes em geral, a imagem mais lembrada é a dos intérpretes de conferência, em suas cabines, com seu equipamento de som, em encontros internacionais, intérpretes de línguas vocais, portanto. No entanto, este tipo de interpretação, o mais prestigiado de todos, não é o único, existem diversas classificações quanto a sua atuação, por exemplo:

- Intérpretes de conferência: participam de eventos em que a interpretação, na sua maioria, é somente em uma direção como em uma palestra em que o conferencista fala quase o tempo todo e, se existem espaços para uma interação dialógica, é somente no final do evento, com tempo restrito. 
- Intérpretes acompanhantes ou de trâmites: acompanham uma pessoa ou grupos pequenos em interações, geralmente, dialógicas tais como, reuniões, entrevistas, consultas, etc.

$\mathrm{Na}$ Classificação Brasileira de Ocupações (CBO) (2006) os intérpretes fazem parte da família dos Filólogos, intérpretes e tradutores e sua identificação é feita sob o código 2614-10 e abrange as denominações de: Intérprete - Intérprete comercial , Intérprete de comunicação eletrônica , Intérprete de conferência ou Tradutor simultâneo. Dentre as suas atribuições, consta que:

Traduzem, na forma escrita, textos de qualquer natureza, de um idioma para outro, considerando as variáveis culturais, bem como os aspectos terminológicos e estilísticos, tendo em vista um público-alvo específico. Interpretam oralmente, de forma simultânea ou consecutiva, de um idioma para outro, discursos, debates, textos, formas de comunicação eletrônica e linguagem de sinais, respeitando o respectivo contexto e as características culturais das partes. Tratam das características e do desenvolvimento de uma cultura, representados por sua linguagem; fazem a crítica dos textos.

Mesmo que de uma forma incorreta, citando a linguagem de sinais, e não o que seria esperado, língua de sinais, os intérpretes de línguas sinalizadas, no Brasil, começam a ser reconhecidos como ocupação, o que constitui um primeiro passo para a constituição de uma profissão. Existem, atualmente, alguns projetos de lei, visando a regulamentação da profissão de tradutor e intérprete de língua de sinais, mas a maioria, senão todos os textos a que tive acesso, encaram nosso ofício de uma forma muito limitada, restringindose ao campo de atuação educacional. Talvez, por influência da política inclusiva do MEC, nossos representantes políticos, não assessorados por especialistas na área, ignoram nossas atuações em conferências, em trâmites e em acompanhamento, fora do ambiente escolar e universitário. 


\section{Diferenças e similitudes}

Existem muitas semelhanças na atuação dos intérpretes de línguas vocais (ILV) e dos intérpretes de língua de sinais (ILS) e em alguns países a categoria reconhece-se como uma só, apenas tendo diferentes línguas de trabalho. É comum, nos Estados Unidos e na Europa encontrarem-se agências em que são oferecidos os serviços de tradução interpretação não só de línguas vocais como também da língua de sinais local. Entretanto, em países em que as pessoas surdas são vistas como incapacitadas ou prejudicadas em sua capacidade de tomar decisões, a interpretação de língua de sinais assume um caráter predominantemente caritativo e assistencial, um favor ou uma missão divina que pressupõe trabalho voluntário, sacrifício e abnegação.

As diferenças entre os ILV e os ILS podem ser assim resumidas:

\begin{tabular}{|l|l|}
\hline Interpretes de línguas vocais & Interpretes de língua de sinais \\
\hline 1.Interpretam de/para as línguas orais. & $\begin{array}{l}\text { 1. Interpretam de/para alguma língua } \\
\text { de sinais. }\end{array}$ \\
$\begin{array}{l}\text { 2. Seus clientes são pessoas ouvintes } \\
\text { de diferentes entornos geográficos. }\end{array}$ & $\begin{array}{l}\text { 2. Seus clientes são pessoas surdas e } \\
\text { ouvintes do mesmo entorno geográfi } \\
\text { co. }\end{array}$ \\
$\begin{array}{l}\text { 3. Seu campo detrabalho limita-se, } \\
\text { normalmente, a encontros internacionais. }\end{array}$ & $\begin{array}{l}\text { quanto as necessidades comunicativas } \\
\text { e de informação de seus clientes. }\end{array}$ \\
\hline
\end{tabular}

Quadro 1: Diferenças entre intérpretes de línguas vocais e intérpretes de língua de sinais, segundo Rodríguez \& Burgos (2001, p. 30)

A esta distinção, acrescento que, na prática profissional, um grande diferencial dos intérpretes de línguas vocais é que os ILS têm seu maior campo de trabalho em instituições de ensino. A ordem de demandas de atuação é inversamente proporcional às dos v. 


\begin{tabular}{|l|l|}
\hline Interpretes de línguas vocais & Interpretes de língua de sinais \\
\hline 1.Tradução escrita & 1. Educação \\
2. Conferência & 2. Trâmites e acompanhamento \\
3. Trâmites e acompanhamento & 3. Conferência \\
4. Educação & 4.Tradução escrita \\
\hline
\end{tabular}

Quadro 2 - Diferenças na atuação de ILV e ILS

A tradução de línguas vocais tem seu maior campo não na interpretação, mas na tradução escrita, seguida da prestigiada interpretação de conferências, logicamente internacionais, alguns trabalhos em trâmites e acompanhamento e escassos trabalhos como intérpretes educacionais, se existir esta atuação entre os ILV. Os ILS são mais procurados exatamente para a interpretação educacional, devido às políticas inclusivas que perseguem as crianças e jovens surdos através da história, logo em seguida os trâmites e acompanhamentos, pois a sociedade em geral não conhece a língua de sinais de maneira funcional, a interpretação de conferências que no caso das pessoas surdas não necessita ser internacional, pois em seu próprio país são como se fossem estrangeiros e, finalmente, a tradução escrita que ainda não tem representatividade, devido a pouca divulgação no uso de uma escrita de língua de sinais.

Existem, ainda, diferenças extralingüísticas no que os ILV e ILS interpretam. Cabe às pessoas ouvintes entenderem por seus próprios meios as pistas contextuais e os ruídos provenientes do ambiente que podem interferir no ato tradutório, porém em um diálogo entre uma pessoa surda e uma ouvinte, se uma conversa ou barulho interfere, o ouvinte, provavelmente, vai sentir-se perturbado ou desconfortável ou até mesmo, tentar para a fonte do distúrbio (pedindo silêncio), a pessoa surda, por sua vez, vai continuar sinalizando, como se nada estivesse acontecendo e o ILS precisa avisá-la que existem ruídos no ambiente que dificultam escutar a voz do intérprete. 


\begin{tabular}{|l|l|}
\hline Interpretes de línguas vocais & Interpretes de língua de sinais \\
\hline Aspectos ligados à língua e a cultura & $\begin{array}{l}\text { Aspectos ligados à língua e a cultura } \\
\text { Ruídos ambientais significativos } \\
\text { Pistas de contextualização ligadas a } \\
\text { prosódia e ao código ligüístico }\end{array}$ \\
\hline
\end{tabular}

Quadro 3 - Informações efetivamente interpretadas pelos ILV e pelos ILS

Além dos ruídos, existem as dicas prosódicas de entonação, emoção, regulação de turnos de fala que estão totalmente fora do alcance das pessoas surdas e que precisam ser reguladas pelos ILS. Uma pessoa ouvinte quando está falando e não manifesta a sua intenção de ceder o turno, mas o ILS que está interpretando faz uma pausa, não de turno, mas para organizar o processo de interpretação, pode equivocadamente emitir uma pista para a pessoa surda de que é sua vez de falar. Este é um aspecto que mereceria mais estudos, a troca de turnos de fala, mediada por interpretação de língua de sinais. Por enquanto, contamos somente com interrogações e bom senso para tentarmos amenizar os descompassos causados pela barreira das diferentes modalidades das línguas envolvidas.

Alguns pesquisadores, dentre eles, Bélanger (2000), pontuam as atuações em língua de sinais diferenciadas daquelas em línguas vocais e outras que, apesar de serem mediações interlingüísticas, não podem ser definidas como interpretações interlíngües:

- Interpretação relé (relais/relay): existe entre línguas vocais, mas é distintiva no caso em que, por exemplo, uma palestra em Inglês seja interpretada diretamente para a Libras e só então para a língua portuguesa. Neste caso o ILS é o intérprete relé. 
- Intérprete tátil: chamado, no Brasil, de guia-intérprete para pessoas surdocegas que utilizam a língua de sinais tátil. Se o mediador estiver utilizando outras técnicas para surdocegos como, pro exemplo, desenhar na palma da mão as letras do alfabeto latino ou tocar nas falanges de acordo com o sistema Braille, então não se trata de uma interpretação interlíngüe, mas sim de uma transliteração.

- Intérprete surdo: uma pessoa surda pode atuar normalmente como intérprete entre duas línguas de sinais. No caso em que uma pessoa surda não é falante competente da Libras e um ILS não consegue estabelecer um entendimento com ela, pode ser chamada outra pessoa surda que por meio gestual consiga uma comunicação primária, mas satisfatória e não se trata de uma interpretação interlíngüe e sim de uma comunicação gestual ou mímica.

- Comunicador pidgin: nesta categoria está o uso do português sinalizado em que o léxico da língua de sinais é encaixado na estrutura da língua vocal, gerando, inclusive, a criação de sinais artificiais para suprir a equivalência literal entre as duas línguas.

- Espelhamento: quando um intérprete, ao invés de interpretar, copia a sinalização de outro intérprete. Este é o caso em que, por motivos de localização no espaço, a platéia surda tem que se posicionar em diversos locais onde não seja possível a visualização de somente um intérprete.

- Duplicador ou Replicador vocal: é chamada assim a pessoa que duplica a fala vocal de outra pessoa para deficientes auditivos que não se sentem proficientes ou confortáveis com a língua de sinais. Não é uma interpretação interlíngüe, pois o duplicador posiciona-se de frente para a pessoa deficiente 
auditiva e, literalmente, reproduz, na mesma língua, tudo o que ouve, com uma articulação cuidadosa.

Em alguns países, a classificação dos ILS chega a requintes segundo a sua titulação. O Register of Interpreters for the Deaf (RID), órgão de registro e supervisão da atuação dos ILS estadunidenses, mantém, atualmente, duas grandes áreas de classificação de intérpretes e cada grande área possui uma complexa subdivisão. É comum que os intérpretes dos EUA apresentem-se ou coloquem em seus cartões de visita seu título de ILS seguido da abreviatura de sua certificação:

- Certificação Nacional de Intérprete (National Interpreter Certification - NIC).

- Certificado de Interpretação e Certificado de Transliteração (Certificate of Interpretation - CI and Certificate of Transliteration - CT).

- Intérprete Surdo Certificado (Certified Deaf Interpreter - CDI)

- Certificado de Transliteração Oral (Oral Transliteration Certificate - OTC).

- Intérprete Educacional (Educational Certificate - Ed: K-12).

- Certificado de Especialista Legal/Jurídico (Specialist Certificate: Legal - SC:L).

O RID vem simplificando o seu complexo sistema de registro de intérpretes, e algumas certificações estão sendo abolidas com o passar dos anos.

No Brasil, não contamos com uma classificação muito detalhada, pois ainda não existe uma entidade de classe nacional que certifique ou valide um plano de carreira, a única classificação que contamos pode ser descrita assim (PEREIRA, 2003): 
- naturais ou empíricos: pessoas bilíngües em Português e Libras que "atuam" como intérpretes, porém sem nenhuma instrução formal para a profissão;

- validados: pessoas que atuam como intérpretes naturais e recebem, por meio da aprovação em um teste, um certificado provisório (validação) para trabalharem como ILS ou

- certificados: aqueles que cursaram algum tipo de formação mais elaborada, normalmente, promovida em parceria com a Feneis.

\section{A relação com as pessoas surdas}

Um dos maiores diferenciais dos ILS é que uma das pessoas a quem ele interpreta é, necessariamente, uma pessoa surda. É inegável que para as pessoas surdas, falantes da Libras, os ILS são, na maioria das ocasiões, no mínimo, desejáveis, no entanto esta relação mistura sensações de gratidão, submissão, disputa e vingança. Gratidão por ter acesso às informações; submissão por alguns, até hoje, estarem acostumados a serem guiados por ouvintes; disputa pelo poder nem sempre igualitariamente compartilhado nas relações ouvintes e ILS e pessoas surdas, e vingança pelos ILS serem os únicos ouvintes submetidos à autoridade de cliente das pessoas surdas no ato tradutório. Para compreender estes sentimentos causados na relação ouvinte e ILS e pessoas surdas é necessário rever como os serviços de interpretação de língua de sinais evoluíram através dos tempos. Descrevo a seguir, baseada em Bar-tzur (1999), os modelos de serviço de interpretação de língua de sinais mais comuns, e faço uma adaptação para a nossa realidade. Os modelos refletem a evolução da relação entre intérpretes ouvintes e pessoas surdas e não são necessariamente classificados pela ordem de seu surgimento, pois ainda convivemos com 
ILS que aderem a comportamentos e ideologias considerados ultrapassados.

\section{Modelo Caritativo}

O modelo caritativo surgiu antes que a interpretação fosse encarada como profissão. A maioria dos intérpretes pertenciam a uma família com pessoas surdas, eram professores de surdos ou religiosos interessados em manter um grupo, comunidade ou ministério de surdos. Cada um tinha algum motivo "nobre" para ajudar as pessoas surdas. Quando queremos ajudar alguém, esta atitude demonstra, de nossa parte, uma pretensa superioridade. As pessoas surdas sentem-se como pessoas menores, diminuídas em suas reais capacidades e à mercê dos ouvintes. Para as pessoas ouvintes que serviam de intérpretes, por laços sangüíneos, pedagógicos ou religiosos, era uma obrigação ir a eventos de surdos e acabavam identificando-se com o mundo surdo. A maioria dos intérpretes não possuía uma formação específica na área da interpretação interlíngüe e utilizavam-se de interpretação consecutiva, para resumir ou modificar o que julgavam que estava além da compreensão das pessoas surdas. Na tentativa de ajudar e proteger as pessoas surdas de erros, aqueles que atuavam como intérpretes, não tinham a noção de sigilo profissional, hoje existente, e compartilhavam informações obtidas nas interpretações com outras pessoas. Foi a partir destas pessoas, que atuavam como intérpretes, que as pessoas surdas começaram a ter acesso às informações do mundo ouvinte, porém apenas recebiam as informações, ainda não tinham nenhum poder decisório.

\section{Modelo Telefone}

Geralmente, quando existe uma reação a um modelo anterior, a tendência é ir-se para o extreme oposto. Não foi diferente quando surgiram as primeiras críticas ao modelo caritativo. De almas boas e caridosas, os intérpretes começaram a querer um tratamento 
mais profissional e acharam-se na obrigação de serem invisíveis, neutros e distantes. A metáfora utilizada, na época, era de que o intérprete teria que ser como um telefone, apenas "passando" a informação de um lado para o outro, sem se envolver e sem manifestar sua subjetividade, acrescento eu. O objetivo era justo, devolver o controle da interação às pessoas surdas e evitar o domínio dos ouvintes porém, quando as pessoas tornam-se invisíveis, apenas canais de comunicação, os seus traços humanos são apagados, tornando-se meros objetos e a sensação de desvalorização começa a tomar conta dos intérpretes. Neste modelo os intérpretes temem uma simbiose com as pessoas surdas, pois afinal, máquinas não interagem. Não se pode negar os avanços que este modelo trouxe à categoria, como a instituição dos primeiros códigos de ética, porém, nesta mesma fase, muitos ILS afastaram-se da profissão por considerarem-se usados e por recusarem-se a ser tratados como máquinas.

\section{Modelo Facilitador da Comunicação}

Depois de ir de um extremo ao outro, começa uma estabilização em um ponto mais conciliatório para ILS e pessoas surdas. Uma atitude mais humana é esperada de ambas as partes. Os ILS assumem mais responsabilidades extratradutórias, como a preparação antes dos eventos, checar o local antes da interpretação (luz, posicionamento, reserva de lugares frontais para as pessoas surdas). As pessoas surdas, por seu lado, percebem a humanidade dos ILS e que todo ser humano tem suas limitações físicas.

\section{Modelo Bilíngüe e Bicultural}

Não só as pessoas surdas deveriam ser bilíngües e biculturais, também os ILS passam a ter a exigência de conhecerem ambas as comunidades em profundidade. Neste caso, o modelo caritativo poderia estar sendo ampliado não só para as pessoas surdas, mas também o ILS deveria ser assistencial com os ouvintes. Para os 
ILS que não são $\mathrm{CODAS}^{3}$, a grande necessidade, neste caso, é um contato e convivência intensos com a comunidade surda na tentativa de tornar-se, o máximo possível, um especialista em surdos. O grande perigo, neste modelo, é que os ILS ultrapassem seus limites na tentativa de serem especialistas em tudo.

Outros modelos estão surgindo, dentre os quais, destaco o Modelo do Aliado, baseado na pedagogia de Paulo freire, que preconiza que o intérprete de língua de sinais deve ser um aliado no empoderamento das pessoas surdas. Em vez de "ajudar", uma relação de desigualdade, existe o "aliar-se" e o compartilhamento do poder. Aqui a figura do ILS mantém-se afastada no momento em que as pessoas surdas devam ser desafiadas a darem suas respostas ao mundo, acertarem e errarem, viverem as conseqüências disto e, principalmente, aprenderem com estas experiências. E aproxima-se nos momentos em que, fora de sua atuação como ILS, pode manter uma interação dialógica de mútua aceitação. Neste modelo, o ILS não tem mais a obrigação de ser um ativista pelos direitos das pessoas surdas, precisa sim evitar perpetuar as práticas opressivas da cultura ouvinte na qual criou-se. A opressão é, muitas vezes, exercida sem a consciência explícita, foi tão naturalizada que se tornou imperceptível. Este modelo exige que a pessoa surda assuma o seu papel nas interações, peça esclarecimentos diretamente ao seu interlocutor ouvinte, e não ao ILS, levante sua mão quando quiser falar e não peça ao ILS que o faça por ele, enfim que não deixe todo o poder nas mãos do ILS e que os dois possam negociar os ajustes a serem feitos. No Modelo do Aliado, diálogo é a palavra-chave entre ILS e surdos, pois,

Certamente, intérpretes que editam o que os falantes estão dizendo, por acharem que a mensagem é politicamente incorreta, religiosamente inaceitável ou não-educada estão sendo um escudo entre pessoas surdas e ouvintes. Não é nosso papel sermos filtros e decidir o que os dois grupos devem saber um do outro (BAR-TZUR, 1999). 
A grande armadilha a evitar, neste modelo emergente, é que os ILS tornem-se o estereótipo negativo do "politicamente correto", exagerando em suas precauções para não oprimir, inadvertidamente, as pessoas surdas.

Infelizmente, não existem muitos trabalhos vindos de pessoas surdas sobre a interpretação de língua de sinais. Ainda não existe uma ampla conscientização de que no ato tradutório as responsabilidades pelo sucesso ou não da interação pertencem a todos os participantes: surdos, ouvintes e ILS. Apesar desta falta de interesse em pesquisas, a vital necessidade dos serviços de interpretação é demonstrada em diversos depoimentos, vários dos quais, transcreverei aqui como reafirmação de que os ILS, para as pessoas surdas, não são um recurso humano complementar na acessibilidade e sim essencial.

Os surdos sentem-se assegurados pelos intérpretes, pois esses, pelo poder de comunicação da língua de sinais, corporificam a possibilidade de resgate da participação. O intérprete ou o tradutor, de qualquer língua, tem grande poder em suas mãos. Ele é responsável pela qualidade da comunicação. Os surdos precisam que esses profissionais sejam bem qualificados (STUMPF, 2005, p. 26).

A falta de disponibilização do serviço de interpretação reforça, nas pessoas surdas, a segregação lingüística a qual a sociedade ouvinte os submete constantemente.

Não vou à maioria das reuniões ou palestras onde não estará um intérprete de língua de sinais. Sinto-me uma boboca em ficar sentada por duas horas em algum lugar sem entender nada. Estou fisicamente presente, mas da palestra aproveito o mesmo tanto quanto a cadeira na qual estou sentada (STRNADOVÁ, 2000, p. 74). 
Muitos ouvintes têm uma visão estereotipada das pessoas surdas como indiferentes, distraídas ou não interessadas em assuntos culturais, mas ignoram a intensidade e duração em que as barreiras lingüísticas estão na vida das pessoas surdas: a todo o momento.

\begin{abstract}
Quantas vezes eu fui chamada de preguiçosa por não prestar atenção aos lábios do professor! Como Lucinda [Ferreira] Brito observou ao dar um curso para nós: de manhã eu tive que prestar atenção no que ela falava e a minha expressão era de preocupação para não perder nada e de tarde veio a intérprete de Libras e a minha expressão mudou, era de alívio, de tranqüilidade, ela comentou isso para os participantes do curso, achei interessante ${ }^{4}$.
\end{abstract}

Existe um mito de que a leitura orofacial (leitura labial) é uma panacéia que pode dar acesso igualitário às pessoas surdas, porém este meio de acesso ao que o outro está dizendo tem várias limitações. A leitura orofacial só pode ser feita com uma pessoa de cada vez (isto exclui os seminários e rodas de conversa) com contato visual e a uma distância próxima, alguns fonemas são pronunciados de uma forma muito parecida, algumas pessoas não têm uma boa articulação ou tapam a boca quando fala, usam barbas e bigodes, etc. Além disto, poucas pessoas que não são da área dos Estudos Surdos reconhecem que a língua portuguesa funciona como segunda língua para a maioria das pessoas surdas.

Joana também enfatizou sua dificuldade no Português. Lamentou o fato de não haver intérprete na faculdade e comentou o quanto lhe era penoso ficar sempre atenta aos lábios de seus professores ouvintes para poder fazer a leitura labial (SOUZA, 1998, p. 112).

$\mathrm{Na}$ escolarização das pessoas surdas, a falta de ILS torna-se um ato de privação de cidadania porque nas instituições educacio- 
nais os ILS são chamados a atuar intensamente. A nãodisponibilização de ILS para as pessoas surdas constitui-se em uma violação dos direitos mais básicos de um ser humano e torna-as sempre as deficitárias e atrasadas em relação às pessoas ouvintes.

Realmente ficava mais tranqüila por tê-lo [o intérprete de língua de sinais] na sala de aula, não precisava fazer esforço para realizar a leitura labial. Neste método entendia apenas $60 \%$, por outro lado, com o intérprete entendia $100 \%$ (...) Concluí o ensino médio numa escola da rede pública, com a atuação deste intérprete o que facilitou o meu aprendizado. Isso me possibilitou olhar meu passado e entender que os surdos necessitavam dos intérpretes (REIS, 2006, p. 22).

Existem depoimentos, em quase todos os trabalhos de pós-graduação de pessoas surdas, reconhecendo o papel fundamental dos intérpretes, como admite Reichert: "Os intérpretes foram muito importantes no andamento do mestrado (2006, p. 94)", mas as tarefas acadêmicas não se resumem à assistência de aulas, existem as participações em eventos, nacionais e internacionais:

Nos poucos em que participei, a interpretação aconteceu de forma precária, contando com a boa vontade de alguém que conhecia a Libras e se dispunha a interpretar minha participação em língua de sinais. Esse dado demonstra como, na maioria das situações, a inclusão é ainda apenas um conceito vazio de conteúdo real (STUMPF, 2005, p. 20).

Stumpf (2005), em sua tese de doutorado, em vários momentos, manifesta-se a favor dos ILS, pois afirma que "Os surdos sentemse assegurados pelos intérpretes, pois esses, pelo poder de comunicação da língua de sinais, corporificam a possibilidade de resgate da participação" e, perceptivamente, põe a descoberto o que o não-oferecimento de ILS demonstra: a hegemonia ouvinte que só a 
si considera e que impõe aos outros que façam todo o esforço para aproximarem-se do que é tido como padrão na nossa sociedade.

Com a língua de sinais os surdos podem, através do intérprete, compreender e ser compreendidos, e os ouvintes, são colocados no mesmo nível, precisam também do intérprete ou de aprender uma língua que não é a sua língua natural (STUMPF, 2005, p. 26).

No entanto somente a presença de um ILS não é garantia de que o processo de acessibilidade alcançou a sua meta porque o acompanhamento das disciplinas e demais atividades acadêmicas não é igualitária entre pessoas surdas e ouvintes.

\begin{abstract}
A presença do intérprete não assegura que questões metodológicas, levando em conta a surdez e os processo especiais/próprios de acesso ao conhecimento, sejam consideradas, ou que o currículo escolar sofra ajustes para contemplar peculiaridades e aspectos culturais da comunidade surda (LACERDA, 2000, p. 57).
\end{abstract}

Muitos professores, constatando a presença de um ILS crêem que não precisam proceder a nenhuma adaptação de suas aulas. Eis a idéia pré-concebida de que um ato tradutório ocorre entre línguas e não entre pessoas. Os docentes acreditam que o problema está resolvido porque uma pessoa que consegue se comunicar em Libras está na aula, porém os problemas advindos da falta de adaptação metodológica e de uma devida mediação permanecem, no mais das vezes, ocultos ou, providencialmente negligenciados.

Esta visão não se restringe ao âmbito escolar, no dia-a-dia, surdos e ouvintes, em geral, têm a expectativa de uma interpretação lingüística que não leve em conta o fator humano. Este assunto é muito produtivo e não pretendo, no espaço deste trabalho, desenvolvê-lo em sua amplitude, porém devo chamar a atenção 
para o fato de que um profissional não-proficiente vai agravar este quadro de incompreensão mútua entre pessoas surdas e ouvintes que não compartilham a mesma língua.

\section{Considerações finais}

Apesar das pessoas surdas serem a meta principal da interpretação de língua de sinais, é importante lembrar que, de um certo modo, também somos intérpretes de língua vocal porque interpretamos da língua de sinais para a língua portuguesa e vice-versa. Intermediamos as interações entre pessoas surdas e pessoas ouvintes, e que ambas precisam de qualidade no serviço de interpretação que recebem. No entanto, o desconhecimento dos aspectos profissionais da interpretação de língua de sinais gera uma mentalidade de serviço assistencial e que não necessita de aporte teórico. Este equívoco tem gerado cursos que não têm preenchido as expectativas de qualificação dos ILS que, inclusive, vêm sendo formados em uma estranha mescla de profissões, denominada de: professores-intérpretes. Os professores-intérpretes são uma invenção criada no rastro da política inclusiva que, aproveitando os professores de pessoas surdas (nem sempre suficientemente proficientes em Libras), fornece cursos de interpretação sucintos e os transforma em professores e intérpretes, na mesma profissão e exercendo ambas as funções no mesmo cargo. Em países com mais tradição e seriedade na formação de ILS, existem os intérpretes educacionais que, mesmo se forem professores, exercem suas profissões de forma independente.

O desconhecimento sobre a atuação dos ILS é uma evidência de nossa marginalização:

1. dos Estudos da Tradução pela carga, ainda, caritativa que a prestação de serviços de interpretação de língua de sinais ainda carrega ("ajudar os surdos") e pela ignorância do estatuto lingüístico da língua de sinais no meio acadêmico; 
2. dos Estudos Surdos, pois é fácil perceber, em um rápido vislumbre nos programas de extensão e pesquisa, que praticamente toda a produção acadêmica concentra-se nas pessoas surdas e nos professores de surdos. Os cursos de especialização e de pós-graduação, de Educação Especial ou Inclusi$\mathrm{va}$, raramente tomam os intérpretes de língua de sinais como merecedores de atenção. Nestes cursos, geralmente, são citadas as legislações que dão suporte ao serviço de interpretação e a necessidade das pessoas surdas, falantes da Libras, dos ILS. Porém o seu papel crucial como participante ativo nas intermediações lingüísticas e culturais entre pessoas surdas e ouvintes não é abordado na profundidade necessária para uma tarefa tão complexa e que requer alto grau de especialização.

Um agente tão presente na garantia dos direitos das pessoas surdas, com tarefas tão, ou mais, complexas do que os intérpretes de línguas vocais, merece ser tirado do obscurantismo e ser alvo de, cada vez mais, estudos acadêmicos.

\section{Notas}

1. Pesquisas sobre um sistema de registro gráfico de línguas de sinais, o Signwriting, estão sendo desenvolvidas, mas sua utilização ainda não é amplamente aceita, não só pelos pesquisadores, mas também pela comunidade surda e demais falantes da Libras. Existe também, em certos casos, a tradução da língua de sinais para a língua portuguesa, na modalidade escrita, o que justifica a denominação completa de tradutores e intérpretes de Libras.

2. Existe a língua de sinais tátil, utilizada por pessoas surdocegas, que não é muito conhecida, pois é preciso ter aprendido a língua de sinais, antes de perder a visão, para poder utilizá-la. 
3. Children of Deaf Adults: parentes e, principalmente, filhos de pais surdos.

4. Depoimento de Irene M. Stock, surda, à Revista da Federação Nacional de Educação e Integração dos Surdos (Feneis). Rio de Janeiro, abril de 2001, p. 24.

\section{Bibliografia}

BAR-TZU, David. Integrating the interpreting service models. In: The Interpreter's Friend. 1999. Disponível em: < http://www.theinterpretersfriend.com/misc/ models.html > Acesso em: 10 jul. 2007.

BÉLANGER, Danielle-Claude. Converser en 2 Temps 3 Mouvements: pour comprendre la communication en présence d'un interprète lsq/français. Dissertação (Mestrado em Comunicação), Université du Québec à Montréal, 2000.

BRASIL. Decreto 5.626, de 22 de dezembro de 2005. Regulamenta a Lei no 10.436, de 24 de abril de 2002, que dispõe sobre a Língua Brasileira de Sinais Libras, e o art. 18 da Lei no 10.098, de 19 de dezembro de 2000. In: Diário Oficial da União de 23 de dez. de 2005, Brasília, 28 p.

CLASSIFICAÇÃO BRASILEIRA DE OCUPAÇÕES (CBO). 2006. Disponível em http://www.mtecbo.gov.br/busca/descricao.asp?codigo=2614-10. Acesso em: 16 jun. 2007.

LACERDA, C. B. F. de. "O intérprete de língua de sinais no contexto de uma sala de aula de alunos ouvintes: problematizando a questão". In: LACERDA, C.B.F. de; GÓES, M.C.R. de (orgs.). Surdez: Processos Educativos e Subjetividade. São Paulo: Editora Lovise, p. 51-84, 2000.

PEREIRA, Maria Cristina Pires. "Profissionalização e Formação de Intérpretes de Libras”. Revista da Feneis. Rio de Janeiro, ano III, n. 18, 2003. p. 26-28. 
REGISTRY OF INTERPRETERS FOR THE DEAF (RID). Disponível em $<$ http://www.rid.org > . Acesso em: 02 jul. 2007.

REICHERT, Andre Ribeiro. Mídia Televisiva sem Som. Dissertação (Mestrado em Educação). Programa de Pós-Graduação em Educação, Universidade Federal do Rio Grande do Sul, 2006.

REIS, Flaviane. Professor Surdo: poesia e poética da transgressão pedagógica. Dissertação (Mestrado em Educação). Programa de Pós-Graduação em Educação , Universidade Federal de Santa Catarina, 2006.

RODRÍGUEZ, Esther de los Santos; BURGOS, $\mathrm{M}^{\mathrm{a}}$ del Pilar Lara. Técnicas de Interpretación de Lengua de Signos. Barcelona: CNSE, 2001.

SÁ, Nídia Regina Limeira de. Educação de Surdos: a caminho do bilingüismo. Niterói: EdUFF, 1999.

SOUZA, Regina Maria de. Que Palavra que te Falta? Lingüistica, educação e surdez. São Paulo: Martins Fontes, 1998.

. "Intuições lingüísticas sobre a língua de sinais, nos séculos XVIII e XIX, a partir da compreensão de dois escritores surdos da época". Revista D.E.L.T.A, os 329-344, v. 19, n. 2, 2003.

STOCK, Irene M. Revista da Federação Nacional de Educação e Integração dos Surdos (Feneis). Rio de Janeiro, abril de 2001, p. 24.

STRNADOVÁ, Vera. Como é Ser Surdo. Tradução de Daniela Richter Teixeira. Petrópolis: Babel Editora, 2000.

STUMPF, Marianne Rossi. Aprendizagem de Escrita de Língua de Sinais Pelo Sistema Signwriting: Línguas de Sinais no Papel e no Computador. Tese (Doutorado em Educação). Programa de Pós-Graduação em Informática na Educação, Universidade Federal do Rio Grande do Sul, 2005. 